\title{
Inhibition of Fc-rosette formation by synovial fluids from patients with rheumatoid arthritis
}

\author{
Y. HASHIMOTO, T. MORITO, K. TANIMOTO, AND Y. HORIUCHI \\ From the Department of Internal Medicine and Physical Therapy, School of Medicine, University of Tokyo, \\ 7-3-1, Hongo, Bunkyo, Tokyo, Japan
}

SUMMARY Human red cells sensitized with one of the Rh antisera (Ripley) form rosettes (Fc-rosetteี with human B lymphocytes and the rosettes are well inhibited by aggregated human IgG. As synovi fy $_{\text {I }}$ fluids from patients with rheumatoid arthritis are usually hypocomplementaemic and frequently contain immune complexes, they were used for the inhibition of Fc-rosette formations in this study

The Fc-rosette inhibitory rates were inversely correlated with the levels of $\mathrm{CH}_{50}$ and $\mathrm{C} 4$ in the synovial fluids. Fractionation studies of the synovial fluids by ultracentrifugation and Sephadex G200 gel filtration indicated that main inhibitory activities were present in macromolecular fractions. Reduction and alkylation of the synovial fluids resulted in marked reductions of inhibitory activities: The tested synovial fluids did not contain anti-HLA activity as assessed by the microcytotoxicity test. The Fc-rosette inhibitory rates were not correlated with the levels of $\mathrm{C} 3$ and immunoglobulins, nor with the activity of rheumatoid factors in the synovial fluids.

These results indicate that the Fc-rosette formations are inhibited by the immune complexes contained in the synovial fluids and it was confirmed that the Fc-rosette inhibition test is a simple and sensitive method for the detection of circulating immune complexes.

Our previous study showed that human red cells sensitized with one of the Rh antisera (Ripley) formed rosettes (Fc-rosette) with some human lymphocytes and these rosettes were well inhibited by hypocomplementaemic systemic lupus erythematosus sera (Morito et al., 1976). The inhibitions were ascribed to the presence of immune complexes in the sera. However, it is well known that complement levels of synovial fluids from patients with rheumatoid arthritis are usually depressed in spite of their relatively high content of total protein (Pekin and Zvaifler, 1964; Bunch et al., 1974), and that immune complexes are frequently detectable in these synovial fluids (Hannestad, 1967; Winchester et al., 1971; Luthra et al., 1975).

In the present study synovial fluids from patients with rheumatoid arthritis were used for the inhibition of Fc-rosette formation, and the inhibitory rates were compared with several parameters including complement levels, immunoglobulin levels, and rheumatoid factor activities. The nature of inhibitory factors in the synovial fluids was analysed using ultracentrifugation and gel filtration.

Accepted for publication July 12, 1976 Correspondence to Dr. K. Tanimoto

\section{Materials and methods}

\section{SYNOVIAL FLUIDS}

Thirty-two synovial fluid samples were obtain from 20 patients with rheumatoid arthritis. All the patients were classified as definite or classieg rheumatoid arthritis according to the criteria of the American Rheumatism Association (Ropes et aq. 1958). In addition, four synovial fluid samples from patients with degenerative joint disease were used in this study. 20 units/ml hyaluronidase (Spraste, Mochida Pharmaceutical, Tokyo) was added each synovial fluid and mucin contained in the synovial fluid was dissolved. All the synovial flüid samples were heat inactivated at $56^{\circ} \mathrm{C}$ for 30 minut

INHIBITION OF FC-ROSETTE FORMATION Human blood type $\mathrm{O}\left(\mathrm{C}^{+} \mathbf{D}^{+}\right)$red cells were washed three times with physiological saline and twice w $0.15 \mathrm{~mol} / 1, \mathrm{pH} 7 \cdot 4$ gelatin veronal buffer $\left(\mathrm{GVB}^{+++^{+}}\right)$ as previously described (Mayer, 1961), and surspended at $2 \times 10^{8} / \mathrm{ml}$. An equal volume of Riple serum 20 times diluted (Waller and Vaughan, 1956) was added to the red cell suspensions and incubated at $37^{\circ} \mathrm{C}$ for 60 minutes, and these were used ${ }^{2} s$ sensitized red cells. Lymphocytes were separatod 
from normal human peripheral blood by the differential centrifugation method using Ficoll-Conray's solution as described previously (Morito et al., 1976).

For the Fc-rosette inhibition, $0.2 \mathrm{ml}$ of the synovial fluid was added to $0.1 \mathrm{ml}$ of $7 \times 10^{6} / \mathrm{ml}$ of lymphocyte suspensions and incubated at $37^{\circ} \mathrm{C}$ for 30 minutes. After incubation the lymphocytes were washed five times with gelatin veronal buffer containing $0.01 \mathrm{~mol} / 1$ ethylene diamine tetra-acetate (EDTA). Equal volumes of $7 \times 10^{6} / \mathrm{ml}$ of the lymphocytes and $1 \times 10^{8} / \mathrm{ml}$ of the sensitized red cells were incubated at $37^{\circ} \mathrm{C}$ for 15 minutes. After centrifugation at $500 \mathrm{rpm}$ for 5 minutes and gentle resuspension, one drop of the suspensions was placed on the microscope slide and lymphocytes surrounded by more than four red cells were considered to be positive rosette forming cells. Fc-rosette formation rates were calculated from a total of $\mathbf{2 0 0}$ lymphocytes. Fc-rosette inhibitory rates of the synovial fluids were estimated in comparison with the rosette forming rate with normal human serum used as control.

\section{FRACTIONATION OF SYNOVIAL FLUIDS BY ULTRACENTRIFUGATION}

Each $3 \mathrm{ml}$ of synovial fluid was centrifuged at $140000 \mathrm{~g}$ for 4 hours using a Hitachi $65 \mathrm{p}$ centrifuge. The synovial fluid was separated into three fractions of $1 \mathrm{ml}$ each, i.e. top, middle, and bottom fractions.

\section{FRACTIONATION OF SYNOVIAL FLUIDS BY} SEPHADEX G200 GEL FILTRATION

Three ml of synovial fluid was applied on Sephadex G200 column (Pharmacia Fine Chemicals, Uppsala, Sweden) equilibrated with $0.15 \mathrm{~mol} / 1, \mathrm{pH} \mathrm{7 \cdot 4}$, phosphate buffered saline (PBS), and separated into five fractions consisting of 1st peak (void volume, 19S fraction), 2nd peak (7S fraction), 3rd peak (albumin fraction), and fractions between them. Each fraction was concentrated by evaporation and used for the Fc-rosette inhibition.

\section{REDUCTION AND ALKYLATION OF SYNOVIAL}

FLUIDS

Synovial fluids were reduced by $0.01 \mathrm{~mol} / 1$ dithiothreitol at room temperature for 30 minutes and alkylated by $0.015 \mathrm{~mol} / 1$ iodoacetamide at $0^{\circ} \mathrm{C}$ for 2 hours as described previously (Tanimoto et al., 1975). They were dialysed against $0 \cdot 15 \mathrm{~mol} / 1, \mathrm{pH} 7 \cdot 4$, PBS for 48 hours and used for the experiments.

MEASUREMENTS OF COMPLEMENT AND IMMUNOGLOBULIN LEVELS

The $\mathrm{CH}_{50}$ of synovial fluid was measured by Mayer's 50\% haemolytic method (Mayer, 1961).
Levels of C3, C4, IgG, IgA, and IgM were determined by single radial immunodiffusion using Partigen's Immunoplate (Behring Institute, W. Germany) (Mancini et al., 1975).

DETECTION OF RHEUMATOID FACTOR ACTIVITY Rheumatoid factor activities in synovial fluids were detected by the latex fixation test using the RA-test (Hyland Lab., Calif.) (Singer and Plotz, 1956) and by the sensitized sheep cell agglutination test described by Heller et al. (1954).

\section{DETECTION OF ANTI-HLA ACTIVITY}

All the synovial fluids were heat inactivated at $56^{\circ} \mathrm{C}$ for 30 minutes and their anti-HLA activities were detected by Terasaki's microcytotoxicity test using 12 different panels of well typed lymphocytes (Terasaki and McClelland, 1964).

\section{Results}

When the Fc-rosette inhibitory rates of synovial fluids from patients with rheumatoid arthritis were compared with those from patients with degenerative joint disease many of the former showed considerable inhibition, while all of the latter failed to inhibit rosette formation significantly (Fig. 1).

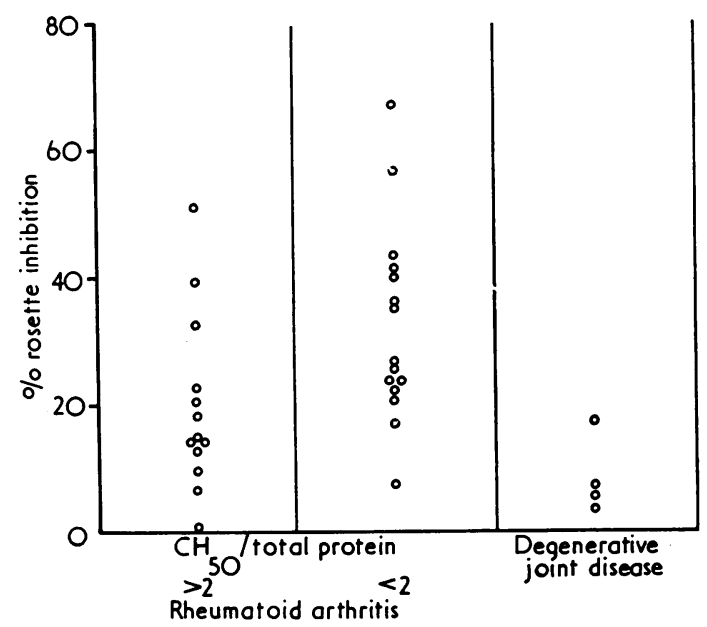

Fig. 1 Fc-rosette inhibition by synovial fluids of patients with rheumatoid arthritis and degenerative joint disease. The $\mathrm{CH}_{50}$ of each synovial fluid was divided by corresponding total protein level $(\mathrm{g} / 100 \mathrm{ml})$ and the ratio plotted against Fc-rosette inhibitory rates. Synovial fluid from patients with rheumatoid arthritis was divided into two groups. In one group $\mathrm{CH}_{50} /$ total protein was $>2 \cdot 0$, and in the other $<2 \cdot 0$. The hypocomplementaemic group showed slightly higher inhibition rates than the normocomplementaemic group and patients with degenerative joint disease. 
Each $\mathrm{CH}_{50}$ value of synovial fluid was divided by the corresponding total protein (TP) level. On the basis of the ratio of $\mathrm{CH}_{50}$ to TP, the synovial fluids from patients with rheumatoid arthritis were divided into two groups. In the hypocomplementaemic group $\mathrm{CH}_{50} / \mathrm{TP}$ values were $<2 \cdot 0$, and in the normocomplementaemic group the values were $>2 \cdot 0$. The hypocomplementaemic group showed higher inhibitory rates than the normocomplementaemic group (Fig. 1). The correlation coefficient

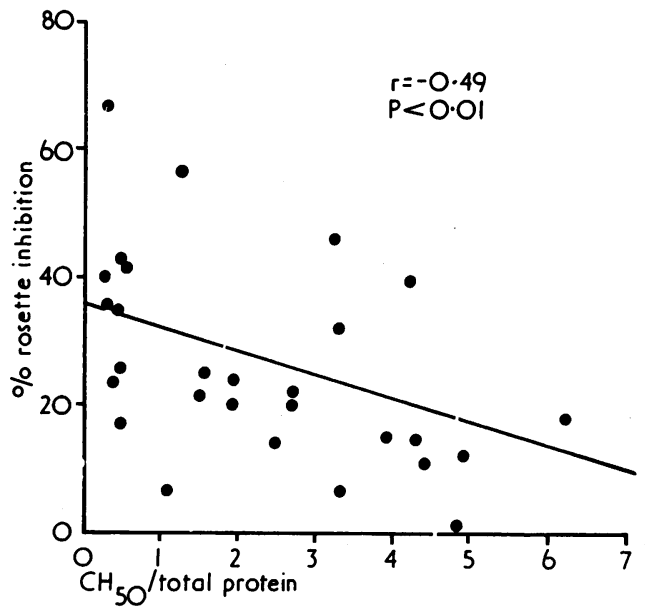

Fig. 2 Relation between Fc-rosette inhibition and $\mathrm{CH}_{50}$ /total protein of rheumatoid synovial fuids. The ratio of $\mathrm{CH}_{50}$ to total protein was plotted against $\mathrm{Fc}$ rosette inhibitory rates. Negative correlation was found between them $(r=-0.49, P<0.01)$.

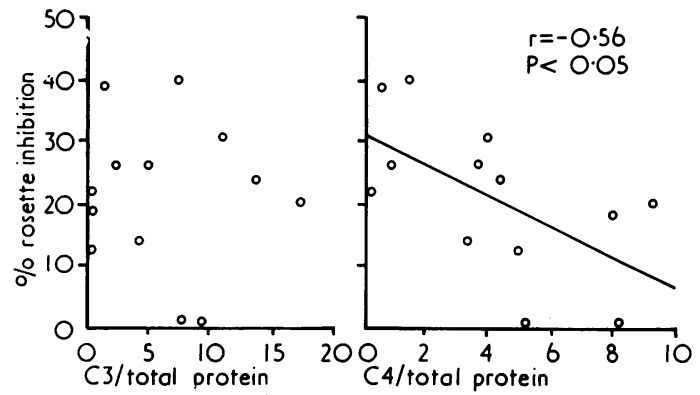

Fig. 3 Relation between Fc-rosette inhibitory rates and C3/total protein and C4/total protein of rheumatoid synovial fluid. The values of C3 and C4 (mg/100 ml) in the synovial fluids were divided by total protein levels $(\mathrm{g} / 100 \mathrm{ml})$. The rates of $\mathrm{C} 3$ and $\mathrm{C} 4$ to total protein were plotted against Fc-rosette inhibitory rates. The correlation between the inhibitory rates and C3/total protein was not significant, but a negative correlation was found between Fc-rosette inhibitory rates and C4/total protein $(r=-0.56, P<0.05)$. between the Fc-rosette inhibitory rates and $\mathrm{CH}_{5}$ TP values was $r=-0.49(\mathrm{P}<0.01)$ (Fig. 2), indi:cating that the lower the complement levels in the synovial fluids the higher the Fc-rosette inhibitor rate.

C3 and C4 levels in synovial fluid were alse compared with Fc-rosette inhibitory rates. Althoug the correlation between $\mathrm{C} 3$ levels and the inhibitory rates did not reach significance, the correlation coefficient of $\mathrm{C} 4$ levels with the inhibitory rates was significant $(r=-0.56, P<0.05)$ (Fig. 3).

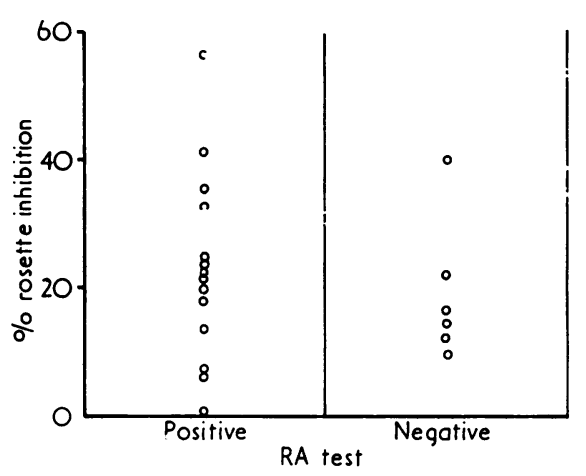

Fig. 4 Relation between Fc-rosette inhibitory rate and RA-test positivity of rheumatoid synovial fluids. The synovial fluids were divided into RA-test positive and negative groups. When the Fc-rosette inhibitory rates of these two groups were compared there were no significan differences.

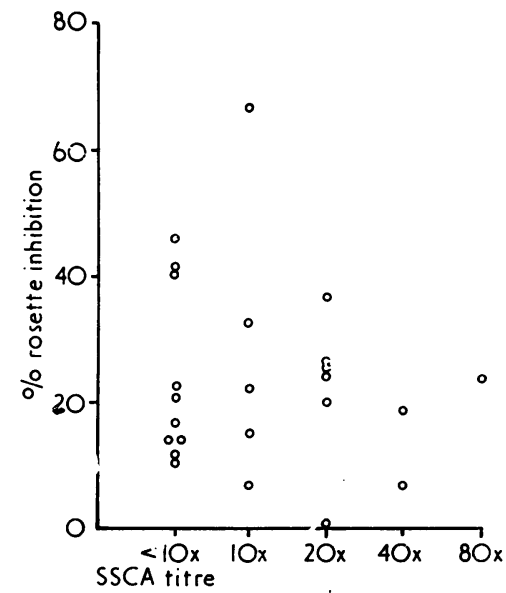

Fig. 5 Relation between $F c$-rosette inhibitory rates and 0 sensitized sheep cell agglutination (SSCA) titres of rheumatoid synovial fuids. SSCA titres in the synovial fluids were determined as described by Heller et al. (1954) The titres were plotted against Fc-rosette inhibitory rates? but no significant correlation was observed. 


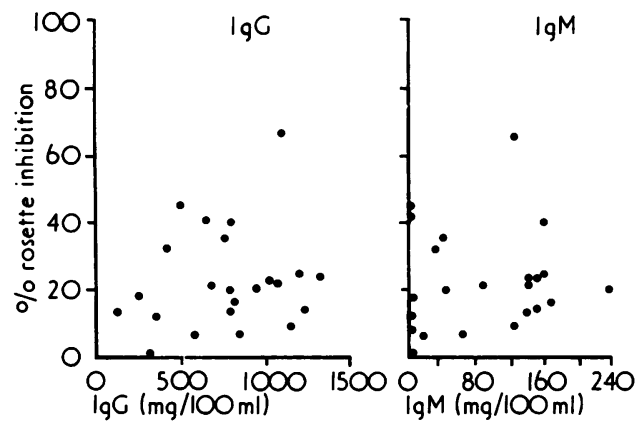

Fc-rosette inhibitory rates were studied in comparison with rheumatoid factor activities and immunoglobulin levels. Neither the results of positive latex fixation tests nor of SSCA titres gave significant correlations with Fc-rosette inhibitory rates (Figs. 4, 5). Levels of $\operatorname{IgG}, \operatorname{IgA}$, and $\operatorname{IgM}$ in the synovial fluids plotted against the corresponding Fc-rosette inhibitory rates (Fig. 6) showed no significant correlations with the inhibitory rates.

Three highly inhibitory synovial fluid samples were centrifuged at $140000 \mathrm{~g}$ for 4 hours, and separated into top, middle, and bottom fractions. When each fraction was tested by the Fc-rosette inhibition test, the bottom fractions were found to be the most inhibitory (Fig. 7).

One synovial fluid sample was applied on Sephadex G200 column and separated into five fractions: 1st peak (void volume 19S fraction), 2nd peak (7S fraction), 3rd peak (albumin fraction), and fractions between them (Fig. 8). These fractions were also used in Fc-rosette inhibition. The strongest inhibi-

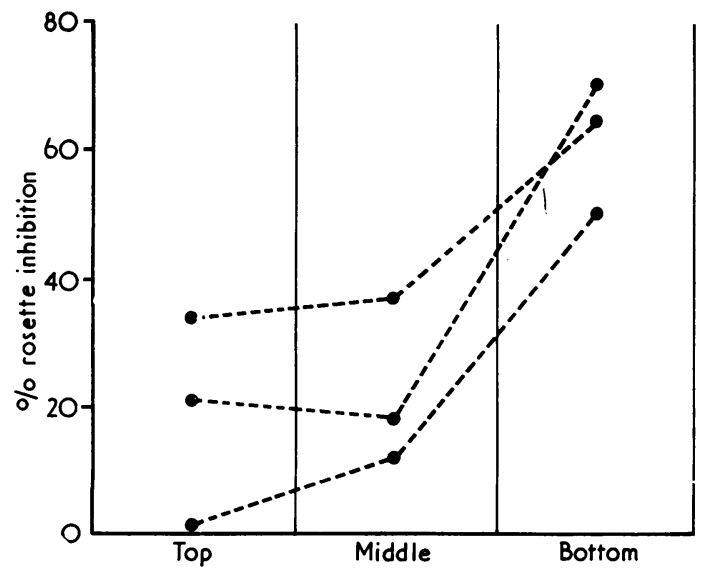

Fig. 7 Inhibition of Fc-rosette by rheumatoid synovial fluids fractionated by ultracentrifugation. Three synovial fluids were separated into top, middle, and bottom fractions by ultracentrifugation at $140000 \mathrm{~g}$ for 4 hours. Each fraction was tested in Fc-rosette inhibition test and bottom fractions were found to be the most inhibitory. tion was observed in the 1st peak, some inhibition was noted in the 2 nd peak and in the fraction between the 1st and 2nd peaks, while the other fractions showed no inhibition.

Synovial fluids conspicuously lost their inhibitory activities after reduction and alkylation (Fig. 9). Anti-HLA activities were not found in the synovial fluids used in this study by the microcytotoxicity test against 12 different panels of lymphocytes.

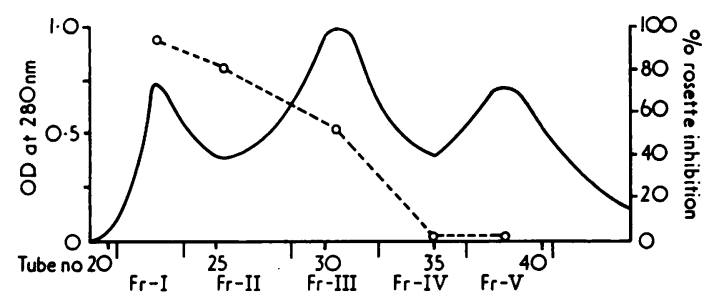

Fig. 8 Inhibition of Fc-rosette by rheumatoid synovial fluids fractionated by Sephadex G200 gel filtration. One synovial fluid was applied on Sephadex G200 column and separated into five fractions. Fc-rosette was most strongly inhibited by Fraction I (Fr-I, 1st peak, void volume); Fr-II and $\mathrm{Fr}-\mathrm{III}$ (7S fraction) showed moderate inhibitions; neither Fr-IV nor Fr-V inhibited rosette formation.

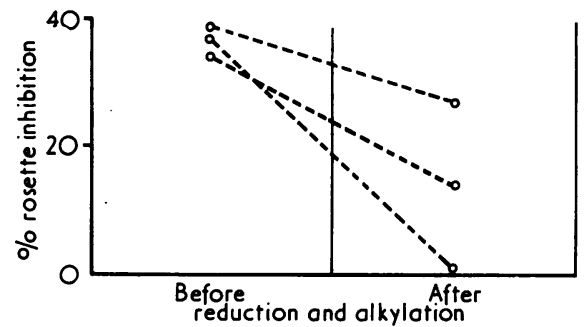

Fig. 9 Effect of reduction and alkylation of rheumatoid synovial fluids on Fc-rosette inhibition. Three synovial fluids were reduced with $0.01 \mathrm{~mol} / \mathrm{l}$ dithiothreitol and alkylated with 0.015 mol/l iodoacetamide. Their FCrosette inhibitory activities were compared before and after reduction and alkylation. The inhibitory activities were moderately to markedly reduced after reduction and alkylation. 


\section{Discussion}

Reports have indicated that immune complexes are frequently present in synovial fluids from patients with rheumatoid arthritis. The methods used were precipitation reactions with rheumatoid factor or $\mathrm{Clq}$, but these methods are generally insensitive. More sensitive methods have also been used, including radioimmunoassay using rheumatoid factor (Cowdery et al., 1975) and the precipitation reaction with monoclonal rheumatoid factor (Winchester et al., 1971). However, radioimmunoassay is not a simple procedure, and it is difficult to determine monoclonal rheumatoid factor.

As noted above, we consider that the Fc-rosette inhibition test used in this study is a simple and sensitive method. With regard to the specificity of this test, Fc-rosette formation may be inhibited not only by immune complexes or aggregated IgG, but also by other factors such as antilymphocyte antibody (Morito et al., 1976). Nevertheless, for the following reasons we think that Fc-rosette inhibition is caused mainly by the presence of immune complexes in synovial fluids.

(1) The hypocomplementaemic group of synovial fluids showed higher Fc-rosette inhibitory rates than the normocomplementaemic group, and the levels of $\mathrm{CH}_{50}$ and $\mathrm{C} 4$ were inversely correlated with the Fc-rosette inhibitory rates. (2) Ultracentrifugation and gel filtration studies indicated that the main inhibitory activities are present in macromolecular fractions. (3) Reduction and alkylation of synovial fluids resulted in marked reduction of the inhibitory activities. (4) None of the tested synovial fluid samples contained anti-HLA activities.

It has been reported that the reactivity of immune complexes with Fc-receptors on lymphocytes disappears after reduction and alkylation (Dickler, 1974), whereas the inhibitory activities of antilymphocyte antibodies are not affected by reduction and alkylation. It may be that rheumatoid factor contained in synovial fluids interferes with rosette formation of the lymphocytes with sensitized red cells. In our study the lymphocyte preparations after reaction with synovial fluids were thoroughly washed and rheumatoid factor activity was no longer detected in the supernates. In addition, there were no significant differences of Fc-rosette inhibitory rates between the rheumatoid factor positive group and the negative group in the synovial fluids. It is therefore unlikely that rheumatoid factor contained in the synovial fluid would inhibit Fcrosette formation.

Antilymphocyte antibodies such as anti-HLA antibodies may inhibit Fc-rosette formation, but the microcytotoxicity test showed none of these antibodies in the synovial fluids. In addition, suct antibodies do not usually lose their inhibitory? activity after reduction and alkylation. In our exper ments, the 7S fraction from synovial fluids showed slight inhibition. Since the fraction might contais peculiar antibodies which are not detected by the microcytotoxicity test, it is possible that thes antibodies inhibit Fc-rosette formation.

In synovial fluids from patients with rheumatoiध̈ arthritis complement levels are usually low in spite of a high protein content (Pekin and Zvaifler, 1964; Bunch et al., 1974). It is generally believed the immune complexes formed in synovial fluids activare the classical complement sequences and result in the reduction of complement levels. In leucocytes frolop the synovial fluids immune complexes and comple ment components have been observed as inclusion bodies (Hollander et al., 1965; Vaughan et a $\int_{\odot}$ 1968), lysosomal enzymes being released from the leucocytes after phagocytosis. Lysosomal enzymes are thought to play an important role in the is flammatory process in rheumatoid arthritis. Thus, immune complexes will be one of the most importari factors in the pathogenesis of rheumatoid arthritis, and the detection of immune complexes has signiff cant value in rheumatoid arthritis. We stress that th Fc-rosette inhibition test is one of the simplest and most sensitive methods for the detection of circulas ing immune complexes in clinical material.

We are grateful to Miss Atsuko Yokoyama, Miș Fumiko Hara, and Miss Yasuko Uchikoba for theit excellent technical assistance.

\section{References}

Bunch, T. W., Hunder, G. G., McDuffie, F. C., O'Brien, P. and Markowitz, H. (1974). Synovial fluid compleme determination as a diagnostic aid in inflammatory joint disease. Mayo Clinic Proceedings, 49, 715-720.

Cowdery, J. S., Jr., Treadwell, P. E., and Fritz, R. B. (1975) $A$ radioimmunoassay for human antigen-antibody con plexes in clinical material. Journal of Immunology, 11 5-9.

Dickler, H. B. (1974). Studies of the human lymphocytte receptor for heat-aggregated or antigen-complexer immunoglobulin. Journal of Experimental Medicine, 140 508-522.

Hannestad, K. (1967). Presence of aggregated $\gamma$ G-globulin certain rheumatoid synovial effusions. Clinical dif Experimental Immunology, 2, 511-529.

Heller, G., Jacobson, A. S., Kolodny, M. H., and Kammerế W. H. (1954). The hemagglutination test for rheumatoif arthritis. II. The influence of human plasma fraction (gamma globulin) on the reaction. Journal of Immunologe 72, 66-78.

Hollander, J. L., McCarty, D. J., Astorga, G., and Castre Murillo, E. (1965). Studies on the pathogenesis of rheumge toid joint inflammation. Annals of Internal Medicine, 6 271-280. 
Luthra, H S., McDuffie, F. C., Hunder, G. G., and Samayoa, E. A. (1975). Immune complexes in sera and synovial fluids of patients with rheumatoid arthritis. Journal of Clinical Investigation, 56, 458-466.

Mancini, G., Carbonara, A. O., and Heremans, J. F. (1965). Immunochemical quantitation of antigens by single immunodiffusion. Immunochemistry, 2, 235-254.

Mayer, M. M. (1961). Experimental Immunochemistry, 2nd ed., p. 133. Thomas, Springfield, Illinois.

Morito, T., Tanimoto, K., Hashimoto, Y., Horiuchi, Y., and Juji, T. (1976). Fc-rosette inhibition by hypocomplementaemic systemic lupus erythematosus sera. Annals of the Rheumatic Diseases, 35, 415-421.

Pekin, T. J., Jr., and Zvaifler, N J. (1964). Hemolytic complement in synovial fluid. Journal of Clinical Investigation, 43, 1372-1382.

Ropes, M. W., Bennett, G. A., Cobb, S., Jacox, R. F., and Jesser, R. A. (1958). Revision of diagnostic criteria for rheumatoid arthritis. Bulletin on Rheumatic Diseases, 9, 175-176.
Singer, J. M., and Plotz, C. M. (1956). The latex fixation test. I. Application to the serologic diagnosis of rheumatoid arthritis. American Journal of Medicine, 21, 888-892.

Tanimoto, K., Cooper, N. R., Johnson, J. S., and Vaughan, J. H. (1975). Complement fixation by rheumatoid factor. Journal of Clinical Investigation, 55, 437-445.

Terasaki, P. I., and McClelland, J. D. (1964). Microdroplet assay of human serum cytotoxins. Nature, 204, 998-1000.

Vaughan, J. H., Barnett, E. V., Sobel, M. V., and Jacox, R. F. (1968). Intracytoplasmic inclusions of immunoglobulins in rheumatoid arthritis and other diseases. Arthritis and Rheumatism, 11, 125-134.

Waller, M. V., and Vaughan, J. H. (1956). Use of anti-Rh sera for demonstrating agglutination activating factor in rheumatoid arthritis. Proceedings of the Society for Experimental Biology and Medicine, 92, 198-200.

Winchester, R. J., Kunkel, H. G., and Agnello, V. (1971). Occurrence of $\gamma$-globulin complexes in serum and joint fluid of rheumatoid arthritis patients: use of monoclonal rheumatoid factors as reagents for their demonstration. Journal of Experimental Medicine, 134, 286-295S. 